Xiaohua Ni • Chaoneng Ji • Gentao Cao • Haipeng Cheng

Lingchen Guo $\cdot$ Shaohua Gu $\cdot$ Kang Ying

Robert Chunhua Zhao • Yumin Mao

\title{
Molecular cloning and characterization of the protein 4.10 gene, a novel member of the protein 4.1 family with focal expression in ovary
}

Received: October 1, 2002 / Accepted: November 11, 2002

\begin{abstract}
Protein 4.1 is an important structural protein that is expressed in erythroid and in a variety of nonerythroid tissues. In mammalian erythrocytes, it plays a key role in regulating the physical properties of mechanical stability and deformability in membranes by stabilizing the spectrinactin interaction. The protein 4.1 family mainly comprises 4.1R, 4.1G (general type), 4.1B (brain type), and 4.1N (neuron type). We identified a novel human 4.1 (4.1O) gene that is $2312 \mathrm{bp}$ in length and encodes a protein of 553 amino acid residues. The protein shared homology with mouse protein 4.1B (identity $38 \%$, similarity $55 \%$ ) with a FERM domain. The expression pattern of the human 4.10 gene in 16 tissues showed that there was a transcript only in ovary, whereas in the remaining 15 tissues, specific bands of the transcript could not be detected. In eight human fetal tissues, the specific bands of the transcript could be detected in skeletal muscle, with lower levels detected in thymus and brain. The $4.1 O$ gene consists of 14 exons and 13 introns and was mapped to Chromosome 9q21-9q22 by bioinformatics analysis.
\end{abstract}

Key words Protein $4.1 \mathrm{O} \cdot \mathrm{MTC}$ panel PCR $\cdot$ Chromosome 9q21-9q22 - Ovary $\cdot$ Tumor

X. Ni $\cdot$ C. Ji $\cdot$ G. Cao $\cdot$ H. Cheng $\cdot$ L. Guo $\cdot$ S. Gu $\cdot$ K. Ying $\cdot$

Y. Mao $(\bowtie)$

State Key Laboratory of Genetic Engineering, Institute of Genetics,

School of Life Sciences, Fudan University, Shanghai 200433, P.R.

China

Tel. +86-21-65643573; Fax +86-21-65642502

e-mail: ymmao@fudan.edu.cn

R.C. Zhao

State Key Laboratory of Experimental Hematology, Institute of

Hematology and Hospital of Blood Diseases, Chinese Academy of Medical Sciences and Peking Union Medical College, Tianjin, P.R. China

The first two authors contributed equally to this work.

\section{Introduction}

Protein 4.1 of red blood cells (4.1R) is a multifunctional protein essential for maintaining erythrocyte shape and membrane mechanical properties, such as deformability and stability, through lateral interactions with spectrin and actin in the skeletal network and vertical interactions with cytoplasmic domains of transmembrane proteins, glycophorin C, and band 3 (Takakuwa 2000). The protein 4.1 family comprises a group of skeletal proteins that mainly includes 4.1R, 4.1G (general type), 4.1B (brain type), and $4.1 \mathrm{~N}$ (neuron type). The proteins are structurally related to erythroid membrane skeletal protein $4.1 \mathrm{R}$, which plays a critical role in determining the morphology and mechanical stability of the red blood cell plasma membrane. 4.1 proteins are characterized by the presence of three main conserved structural and functional domains. The FERM domain (F, 4.1; E, ezrin; R, radixin; $M$, moesin) (Chishti et al. 1998), a 30-kDa N-terminal membrane-binding domain, possesses binding sites for the cytoplasmic tails of integral membrane proteins such as band 3 (Pasternack et al. 1985; Lombardo et al. 1992), glycophorin C (Marfatia et al. 1995), CD44 (Nunomura et al. 1997), and Drosophila neurexin (Ward et al. 1998). The FERM domain also binds to p55 (Marfatia et al. 1995) and calmodulin (Tanaka et al. 1991), the latter interaction being important for regulating the affinity of $4.1 \mathrm{R}-$ band 3 and $4.1 \mathrm{R}-\mathrm{CD} 44$ interactions (Nunomura et al. 1997). An internal 8- to 10-kDa domain contains the critical spectrin-actin binding activity required for membrane stability (Schischmanoff et al. 1995), and the C-terminal 22- to 24-kDa domain has been reported to bind the immunophilin FKBP13 (Walensky et al. 1998) and NuMA (Mattagajasingh et al. 1999).

\section{Materials and methods}

A cDNA library was constructed with a modified pBluescrip II SK $(+)$ vector by using 18 -week-old human 
Table 1. Nucleotide sequence of exon-intron junctions of the human $4.1 O$ gene

\begin{tabular}{|c|c|c|c|c|c|}
\hline 3' Splice acceptor & Exon & Size (bp) & 5' Splice donor & Intron & Size $(b p)$ \\
\hline cDNAend AGATTGGAGCCC & 1 & 132 & CAGCTTTCAAAGgtatgtgtcagt & 1 & 77909 \\
\hline cttcctttgcagAGGGAAACCAAA & 2 & 105 & GAGAAGCAAAGGgtaagagctgat & 2 & 16648 \\
\hline tttcctccetagCACTGGCTTGAA & 3 & 43 & AGCAAATGAAAAgtaagtgtcaat & 3 & 23155 \\
\hline atgatgtttcagCTCATCCACCAT & 4 & 79 & AGAGCTCACAAGgtatttttgtt & 4 & 6391 \\
\hline tttgtattgcagATACCТTTTATA & 5 & 98 & GTATTGTTCAAGgtaagtctggce & 5 & 7550 \\
\hline cactcattacagCTGAGCTTGGTG & 6 & 125 & AAATGAACTCAGgtaattactgag & 6 & 21768 \\
\hline gtgtgattttagGGGGCAGAGCCC & 7 & 88 & CACCCATGCAAGgtaactgccect & 7 & 1684 \\
\hline ttttttttcagGATTCAACAGGC & 8 & 89 & TTTGATAAAATGgtaagtgcctct & 8 & 1338 \\
\hline ttcttttcttagGCCAGATGTCTG & 9 & 64 & ACCCAGAAGGAGgtcagatactgc & 9 & 860 \\
\hline ttttttaattagAAAAAAGCCATG & 10 & 89 & GGCCTTTTATAAgtaagtggettt & 10 & 10349 \\
\hline tttttcttaaagGTATGCAAAATC & 11 & 75 & ATTTCGATATAGgtgggtaccaat & 11 & 295 \\
\hline tgtcttttgcagTGGGAAAGTTGC & 12 & 69 & TGAGGTGCACAGgtgagtggatga & 12 & 8020 \\
\hline gtctgttttcagAGCCAACATTAC & 12 & 125 & CTCTGGGTGAGGgtaagtctgtct & 13 & 42086 \\
\hline gtctctttacagGTGTTCCATTGC & 14 & 1130 & AAAAAAAAAAAA & & \\
\hline
\end{tabular}

The intron sequence is shown in lowercase letters and the exon sequence is shown in uppercase letters

fetal brain mRNA (Clontech, Palo Alto, CA, USA). A 0.5$\mathrm{kb}$ DNA fragment containing Sfi (5'-GGCCATTATG GCC-3') and SfiB (5'-GGCCGCCTCGGCC-3') recognition sites was cloned into EcoRI and NotI sites of pBluescript II SK (+) (Stratagene, La Jolla, CA, USA); the modified vector was then digested by SfiI and the large fragment was excised and purified for library construction. A cDNA library was constructed by following the SMART polymerase chain reaction (PCR) cDNA library construction kit protocol (Clontech).The cDNA inserts were sequenced on an ABI PRISM 377 DNA sequencer (PerkinElmer, San Francisco, CA, USA) using the BigDye Terminator Cycle Sequencing Kit and BigDye Primer Cycle Sequencing Kit (Perkin-Elmer) with a -21M13 primer. An M13Rev primer and synthetic internal walking primers were designed according to the obtained cDNA sequence fragments. Each part of the inset was sequenced at least three times bidirectionally. Subsequent editing and assembly of all the sequences from one clone was performed using Acembly (Sanger Centre Cambs, UK).

\section{Results}

From our large-scale sequencing analysis of human cDNA libraries, we cloned a full-length cDNA of the human $4.1 O$ gene, encoding a homologue of the mouse $4.1 B$ gene and the human $4.1 B$ gene. The nucleotide sequence has been submitted to the Genbank/EMBL database with accession number AY137774. The cDNA consists of $2312 \mathrm{bp}$ and contains an open reading frame (ORF) of 1662 bp encoding a protein of 553 amino acids. Using domain analysis on the web service of the National center for Biotechnology Information (NCBI; RPS-BLAST), the FERM domain was found to be located at residues 6-181 (91.6\% aligned) of the protein sequence. The cDNA is considered to be full length because there is an upstream in-frame stop codon (TAG) and polyA signals (AATAAA) after the ORF (Fig. 1A). Bioinformatics analysis using BLASTx revealed that $4.1 \mathrm{O}$ shared homology with AK094281 protein (93\% identity and
93\% similarity), mouse 4.1B (m4.1B, mDAL-1, 38\% identity and $55 \%$ similarity), and human 4.1B (h4.1B, hDAL-1, $38 \%$ identity and $56 \%$ similarity). The predicted protein AK094281, which is mapped to chromosome 9, has 460 amino acids. Because of the difference in the N-terminal and $\mathrm{C}$-terminal amino acid sequence, and no upstream inframe stop codon, it may not be considered full length and is likely to be a splicing variant of 4.1O. Various levels of homology with the FERM domain of AK094281 protein, 4.1G, $4.1 \mathrm{~N}$, and 4.1R were also detected (Fig. 1B).

To determine the chromosomal localization of the human protein $4.1 O$ gene, we used the international human genome database on NCBI. The gene was mapped to contig NT-023935.11, spanning $220364 \mathrm{bp}$. The contig was located at $9 \mathrm{q} 21-9 \mathrm{q} 22$, whereas $4.1 \mathrm{R}, 4.1 \mathrm{~N}, 4.1 \mathrm{G}$, and $4.1 \mathrm{~B}$ were located at 1pter-p34, 20q11.2-q12, 6q23, and 18p11.32. Comparing our cDNA with the genome sequence of $4.1 \mathrm{O}$ suggested that the gene consisted of 14 exons and 13 introns. All sequences at the exon-intron junctions were consistent with the AG-GT rule (Table 1).

The tissue distribution of protein 4.10 was determined by two human multiple tissue cDNA (MTC) panels, a human fetal panel, and a human tumor panel (Clontech, Palo Alto, CA, USA), which were used as PCR templates according to the manufacturer's protocol. The sequences for human $4.1 O$ specific primer pairs were $5^{\prime}$-CTGGCTTG AACCTAACAAGTCCATCT-3' (4.1O F, from 241 to 266 bp) and 5'-CAGGCAGCTGGTGTTGAAGTATGG AAT-3' (4.1O R, from 841 to $866 \mathrm{bp}$ ). Thirty-six cycles of amplification $\left(30 \mathrm{~s}\right.$ at $94^{\circ} \mathrm{C}, 30 \mathrm{~s}$ at $60^{\circ} \mathrm{C}$, and $1 \mathrm{~m}$ in at $72^{\circ} \mathrm{C}$ ) were performed using ELONGASE DNA polymerase (GIBCO BRL, Gaithersburg, MD, USA). The PCR product of $4.1 O$ was then resolved on a $1.5 \%$ metaphor agarose gel (FMC, Philadelphia, PA, USA). In total, 16 human tissues were tested (Fig. 2A). Our data revealed a transcript only in ovary, whereas in the remaining 15 tissues, specific bands of the transcript could not be detected. For this focal expression, we termed AY137774 4.10 (ovary type). In eight human fetal tissues, we found a transcript in skeletal muscle, with lower levels in thymus and brain (Fig. 2B). Additionally, in the human tumor panel we found that, in 
A

1 GAGATTGAAGCCC TAGAGCTCCCAGAGACAGAAGACGAGATGGCAGTATTTTAAGGCACT

61

121

GCAGCTTTCAAAGAGGGAAACCAAAGGGCAGTTTCTCATTTACCACATCTGCAACTACT

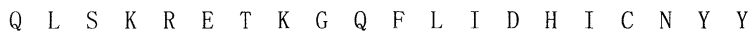

CAGCCTGCTGGAGAAGGACTACTTTGGCATTCGCTATGTGGACCCAGAGAAGCAAAGGCA

$\begin{array}{llllllllllllllllllll}S & L & L & E & K & D & Y & F & G & I & R & Y & V & D & P & E & K & Q & R & H\end{array}$

CTGGCTTGAACCTAACAAGTCCATCTTCAAGCAAATGAAAACTCATCCACCATACACCAT

$\begin{array}{llllllllllllllllllll}W & \mathrm{~L} & \mathrm{E} & \mathrm{P} & \mathrm{N} & \mathrm{K} & \mathrm{S} & \mathrm{I} & \mathrm{F} & \mathrm{K} & \mathrm{Q} & \mathrm{M} & \mathrm{K} & \mathrm{T} & \mathrm{H} & \mathrm{P} & \mathrm{P} & \mathrm{Y} & \mathrm{T} & \mathrm{M}\end{array}$

GTGCTTTAGAGTGAAATTCTACCCACATGAACCCTTGAAGATTAAAGAAGAGCTCACAAG

$\begin{array}{lllllllllllllllllllll}C & \mathrm{~F} & \mathrm{R} & \mathrm{V} & \mathrm{K} & \mathrm{F} & \mathrm{Y} & \mathrm{P} & \mathrm{H} & \mathrm{E} & \mathrm{P} & \mathrm{L} & \mathrm{K} & \mathrm{I} & \mathrm{K} & \mathrm{E} & \mathrm{E} & \mathrm{L} & \mathrm{T} & \mathrm{R}\end{array}$ 361 ATACCTTTTATACCTTCAGATTAAAAGGGACATTTTTCATGGCCGCCTGCTGTGCTCCTT

$\begin{array}{llllllllllllllllllllllllllll}Y & L & L & Y & L & Q & I & K & R & D & I & F & H & G & R & L & L & C & S & F\end{array}$

TTCTGATGCTGCCTACCTGGGTGCCTGTATTGTTCAAGCTGAGCTTGGTGATTACGATCC

$\begin{array}{llllllllllllllllllllllllllll}S & D & A & A & Y & L & G & A & C & I & V & Q & A & E & L & G & D & Y & D & P\end{array}$

481

TGATGAGCATCCTGAGAATTACATCAGTGAGTTTGAGATTTTCCCCAAGCAGTCACAGAA

$\begin{array}{lllllllllllllllllllllll}\text { D } & \text { E } & H & \text { P } & \text { E } & N & \text { Y } & \text { I } & \text { S } & \text { E } & \text { F } & \text { E } & \text { I } & \text { F } & \text { P } & \text { K } & \text { Q } & \text { S } & \text { Q } & \text { K }\end{array}$

541 GCTGGAAAGAAAAATAGTGGAAATTCATAAAAATGAACTCAGGGGGCAGAGCCCACCAGT

$\begin{array}{llllllllllllllllllll}\mathrm{L} & \mathrm{E} & \mathrm{R} & \mathrm{K} & \mathrm{I} & \mathrm{V} & \mathrm{E} & \mathrm{I} & \mathrm{H} & \mathrm{K} & \mathrm{N} & \mathrm{E} & \mathrm{L} & \mathrm{R} & \mathrm{G} & \mathrm{Q} & \mathrm{S} & \mathrm{P} & \mathrm{P} & \mathrm{V}\end{array}$

601 TGCCGAATTTAACTTGCTCCTGAAAGCTCACACTTTGGAAACCTACGGGGTGGATCCTCA

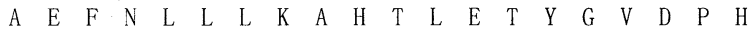

661 CCCATGCAAGGATTCAACAGGCACAACAACATTTTTAGGATTCACAGCTGCAGGCTTTGT

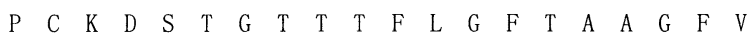

721 GGTCTTTCGGGGAAATAAGAGAATCCATTTGATAAAATGGCCAGATGTCTGCAAATTGAA

$\begin{array}{lllllllllllllllllllll}\mathrm{V} & \mathrm{F} & \mathrm{R} & \mathrm{G} & \mathrm{N} & \mathrm{K} & \mathrm{R} & \mathrm{I} & \mathrm{H} & \mathrm{L} & \mathrm{I} & \mathrm{K} & \mathrm{W} & \mathrm{P} & \mathrm{D} & \mathrm{V} & \mathrm{C} & \mathrm{K} & \mathrm{L} & \mathrm{K}\end{array}$

781 GTTTGAAGGGAAGACATTTTATGTGATTGGCACCCAGAAGGAGAAAAAAGCCATGTTGGC

$\begin{array}{lllllllllllllllllllll}F & E & G & K & T & F & Y & V & I & G & T & Q & K & E & K & K & A & M & L & A\end{array}$

841 ATTCCATACTTCAACACCAGCTGCCTGCAAACATCTTTGGAAGTGTGGAGTGGAAAACCA

$\begin{array}{lllllllllllllllllllll}\mathrm{F} & \mathrm{H} & \mathrm{T} & \mathrm{S} & \mathrm{T} & \mathrm{P} & \mathrm{A} & \mathrm{A} & \mathrm{C} & \mathrm{K} & \mathrm{H} & \mathrm{L} & \mathrm{W} & \mathrm{K} & \mathrm{C} & \mathrm{G} & \mathrm{V} & \mathrm{E} & \mathrm{N} & \mathrm{Q}\end{array}$

901 GGCCTTTTATAAGTATGCAAAATCCAGTCAGATCAAGACTGTATCAAGCAGCAAGATATT

$\begin{array}{lllllllllllllllllllll}\text { A } & F & Y & K & Y & A & K & S & S & Q & I & K & T & V & S & S & S & K & I & F\end{array}$

961 TTTTAAAGGAAGTAGATTTCGATATAGTGGGAAAGTTGCCAAAGAGGTGGTGGAGGCCAG

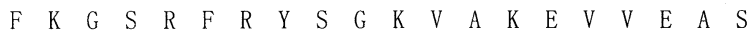

1021 TTCCAAGATCCAGAGGGAGCCTCCTGAGGTGCACAGAGCCAACATTACTCAGAGCCGCAG

$\begin{array}{llllllllllllllllllll}\mathrm{S} & \mathrm{K} & \mathrm{I} & \mathrm{Q} & \mathrm{R} & \mathrm{E} & \mathrm{P} & \mathrm{P} & \mathrm{E} & \mathrm{V} & \mathrm{H} & \mathrm{R} & \mathrm{A} & \mathrm{N} & \mathrm{I} & \mathrm{T} & \mathrm{Q} & \mathrm{S} & \mathrm{R} & \mathrm{S}\end{array}$

Fig. 1. A Nucleotide and deduced amino acid sequences of the $4.1 O$ gene (GenBank accession number AY137774). The nucleotide sequence of the 2312-bp cDNA is shown in the top lines, and its predicted amino acid sequence is shown below in single-letter code. Numbers on the left refer to the first nucleotide in each corresponding line. The open reading frame extended from nucleotide 119 to 1780 and encoded a

colon adenocarcinoma CX-1, colon adenocarcinoma GI112, lung carcinoma GI-117, lung carcinoma LX-1, prostatic adenocarcinoma PC3, ovarian carcinoma GI-102, breast carcinoma GI-101, and pancreatic adenocarcinoma GI-103, specific bands of the transcript could not be detected (data not shown).

\section{Discussion}

Earlier studies show that the protein 4.1B gene, $D A L-1$ (differentially expressed in adenocarcinoma of the lung), is lost in approximately $60 \%$ of non-small cell lung carcinomas, and exhibits growth-suppressing properties in lung cancer cell lines. When $D A L-1$ was reintroduced into nonexpressing non-small cell lung carcinoma cell lines, it
1081 TTCCCACTCCTTGAACAAACAGCTCATCATTAACATGGAACCCCTGCAGCCCCTGCTTCC

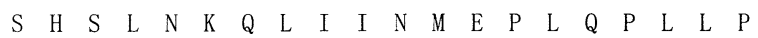
1141 TTCCCCCAGCGAGCAAGAAGAAGAACTTCCTCTGGGTGAGGGTGTTCCATTGCCTAAAGA

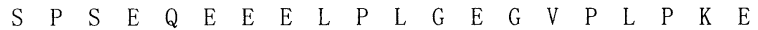
1201 GGAGAACATTTCTGCTCCCTTGATCTCCAGCTCCCCAGTGAAGGCAGCCCGGGAGTATGA $\begin{array}{lllllllllllllllllllll}\text { E } & N & I & S & A & P & L & I & S & S & S & P & V & K & A & A & R & E & Y & E\end{array}$

1261 AGATCCCCCTAGTGAAGAGGAAGATAAAATAAAAGAAGAACCTTTAACCATCTCTGAACT $\begin{array}{llllllllllllllllllllllllllllllll}D & P & P & S & E & E & E & D & K & I & K & E & E & P & L & T & I & S & E & L\end{array}$ 1321 AGTGTACAACCCAAGTGCCAGCCTGCTCCCCACCCCTGTGGATGACGATGAGATTGACAT $\begin{array}{llllllllllllllllllll}V & \text { Y } & N & \text { P } & \text { S } & \text { A } & \text { S } & \text { L } & \text { L } & \text { P } & \text { T } & \text { P } & \text { V } & \text { D } & \text { D } & \text { D } & \text { E } & \text { I } & \text { D } & M\end{array}$ 1381 GCTCTTTGACTGTCCTTCTAGGCTTGAGTTGGAAAGAGAAGACACAGATTCATTTGAGGA $\begin{array}{llllllllllllllllllll}L & F & D & C & P & S & R & L & E & L & E & R & E & D & T & D & S & F & E & D\end{array}$ 1441 TCTGGAAGCAGATGAAAACGCCTTTTTGATTGCTGAAGAAGAGGAGCTGAAGGAGGCTCG $\begin{array}{llllllllllllllllllll}\mathrm{L} & \mathrm{E} & \mathrm{A} & \mathrm{D} & \mathrm{E} & \mathrm{N} & \mathrm{A} & \mathrm{F} & \mathrm{L} & \mathrm{I} & \mathrm{A} & \mathrm{E} & \mathrm{E} & \mathrm{E} & \mathrm{E} & \mathrm{L} & \mathrm{K} & \mathrm{E} & \mathrm{A} & \mathrm{R}\end{array}$ 1501 CCGTGCTTTGTCGTGGAGCTATGACATTCTGACTGGCCATATTCGGGTGAACCCACTGGT $\begin{array}{llllllllllllllllllll}R & A & L & S & W & S & Y & D & I & L & T & G & H & I & R & V & N & P & L & V\end{array}$ 1561 CAAGAGTTTTTCCAGGCTCCTTGTGGTGGGCCTGGGACTGCTGCTCTTTGTATTTCCCCT $\begin{array}{lllllllllllllllllllll}K & S & F & S & R & L & L & V & V & G & L & G & L & L & L & F & V & F & P & L\end{array}$ 1621 GCTCCTCCTCCTTTTGGAGTCAGGTGTTGATCTCTCCTTCTTATGCGAAATCCGCCAGAC

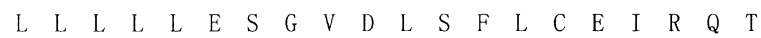
1681 ACCAGAGTTTGAGCAGTTTCACTATGAATACTACTGTCCCCTCAAGGAGTGGGTGGCTGG $\begin{array}{lllllllllllllllllllllllllllll}P & E & F & E & Q & F & H & Y & E & Y & Y & C & P & L & K & E & W & V & A & G\end{array}$ 1741 GAAAGTCCACCTCATCCTCTACATGCTGGGTTGCTCATGAAGTTAATCTCTCATGTGACT $\begin{array}{lllllllllllllllllll}K & V & H & \text { L } & \text { I } & \text { L } & \text { Y } & \text { M } & \text { L } & G & \text { C } & \text { S } & *\end{array}$

1801 AAGGGCTATATTCAATGCTGTGATTTCTTTTTTTCAGCAAATGCCTGGTTCTGAAGGGTC 1861 ACGGGGCTGTCAACAGGTGTTCCTTACTCATAATTGATTATTCAAACCTTTAAGTTAGCT 1921 TTCCATAATTCACTGCACTTAAATAAGTTTAAATCAAATACAGTTATTTTAGTTACAGGT 1981 TAGGAAGATGGTCTTTAAATAACCAAAAATATGTTTATTTTTTATTATAGTGTAGACATA 2041 CCCTTCATCTATTATATCATAATACATGTTACATTGGACTGAATTAGATTTTCCCATTTC 2101 TAATAGTTGGCACCATTATAAGCTATAAGGTTCAGAATCAGAATTTTAGTAACAACTCAA 2161 GAGAAAGTTGTTGAATATAATCCTTAGTGAAAACAGTGTCCTCTAACCAATGCCTATACA 2221 ACTAAATTTATGCTGGGTTTTTGGTTTTGTTTTTTTAAAAATATTTTTATGTGTTCAAAC 2281 TATTTTGGTAAATTTTTAGCAAAAAAAAAAAA

protein of 553 amino acids. An asterisk indicates the terminator in the protein sequence. B A FERM domain alignment of human 4.10 with AK094281 protein, m4.1B, h4.1B, h4.1R, h4.1G, and h4.1N. Numbers on the right refer to the last amino acid in each corresponding line. Identity is indicated by a black box, and similarity is indicated by a gray box

was shown to suppress growth. In addition, significantly reduced expression $(>50 \%)$ of $D A L-1$ was measured in 39 primary non-small cell lung carcinoma tumors as compared with patient-matched normal lung tissue. DAL-1 is thought to be a membrane-associated protein with the potential to play an important role in the origin and progression of lung cancer (Tran et al. 1999). In addition, by using loss of heterozygosity, reverse transcriptase-PCR, Western blot, and immunohistochemistry analyses, Gutmann et al. (2000) found DAL- 1 loss in $60 \%$ of sporadic meningiomas. Analogous to merlin, DAL-1 loss is an early event in meningioma tumorigenesis that suggests these two protein 4.1 family members are critical growth regulators in the pathogenesis of meningiomas. Furthermore, DAL-1 suppresses cell proliferation in meningioma, but not in schwannoma cells. Similar to merlin, DAL-1 interacts with other ERM proteins and betaII-spectrin, but not the merlin interactor 


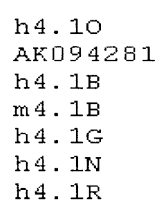

h 4.10

AKO94281

h4. 1B

m $4.1 \mathrm{~B}$

h $4.1 \mathrm{G}$

h $4.1 \mathrm{~N}$

h $4.1 \mathrm{R}$

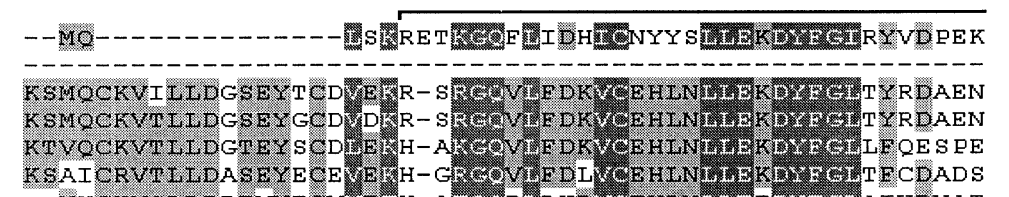

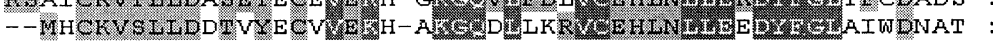

38

160

168

268

147

51

FERM domain

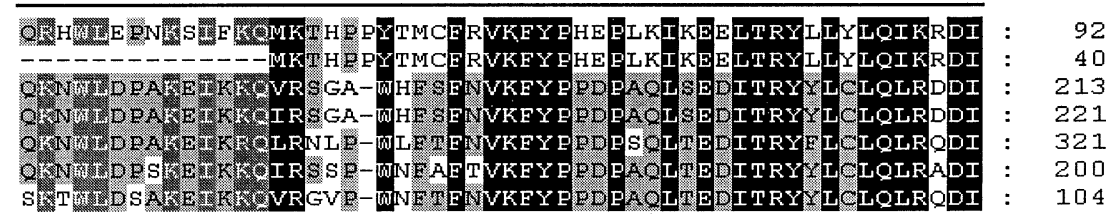

146

94

267

275

375

254

158

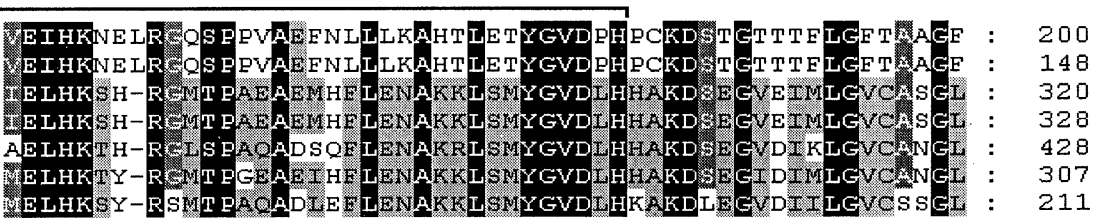

h4. 10 AKO94281

h $4.1 \mathrm{~B}$

m 4. 1B

h4. $1 \mathrm{G}$

h $4.1 \mathrm{~N}$

h4. 1 R
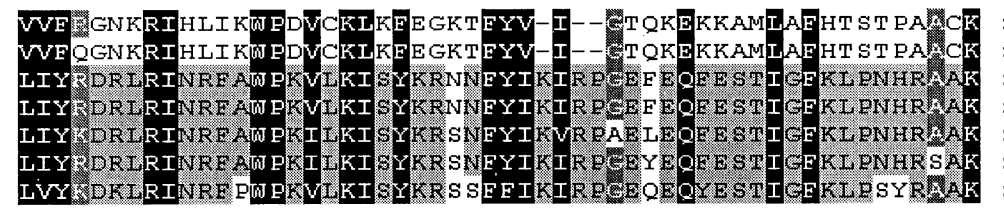

251

protein, SCHIP-1. These observations suggest that the two protein 4.1 meningioma tumor suppressors, merlin and DAL-1, may be functionally distinct proteins with different mechanisms of action (Gutmann et al. 2001).

We report here a novel human band 4.1 (4.1O) gene, which, by bioinformatics analysis from NCBI, is found to be located at chromosome $9 \mathrm{q} 21-9 \mathrm{q} 22$, whereas $4.1 R, 4.1 N$,
$4.1 G$, and $4.1 B$ are located at a different chromosome. $4.1 O$ is $2312 \mathrm{bp}$ in length and encodes a protein of 553 amino acid residues in which the 4.1 family domain (FERM) is identified. By BLASTx at NCBI, we found that the predicted protein shares homology with mouse 4.1B (38\% identity and 55\% similarity) and human 4.1B (37\% identity and $55 \%$ similarity). In the cerebellum, $4.1 O$ expresses in 
Fig. 2A, B. Tissue distribution of 4.1O expression in normal tissue and fetal tissue. A Tissue distribution of 4.10 expression in human normal tissue. G3PDH, Glucose-3-phosphate dehydrogenase. B Tissue distribution of $4.1 O$ expression in human fetal tissue
$\mathbf{A}$

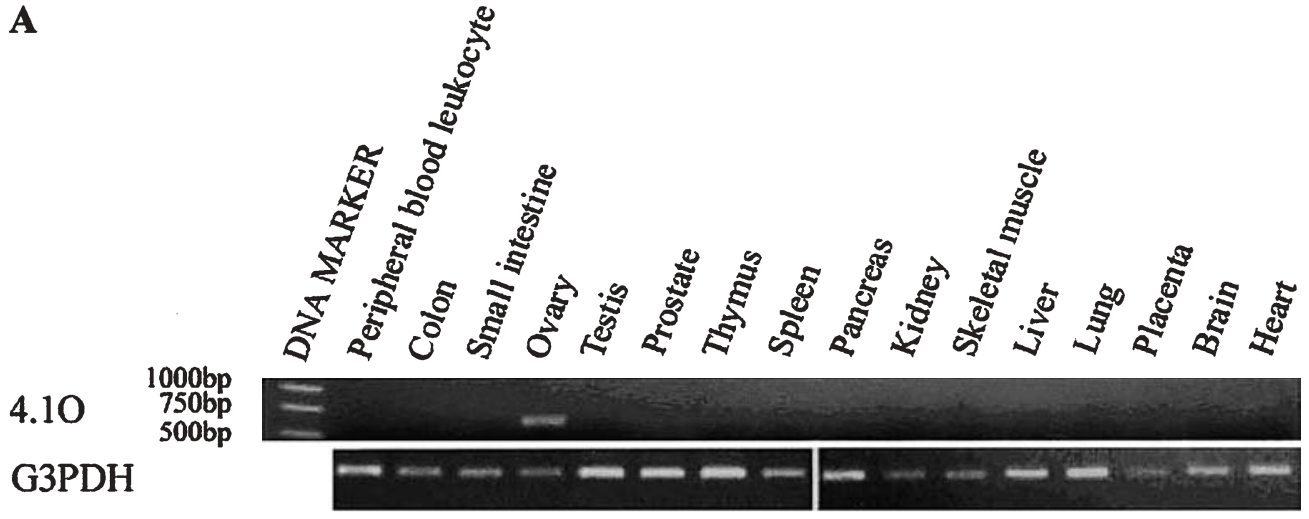

B

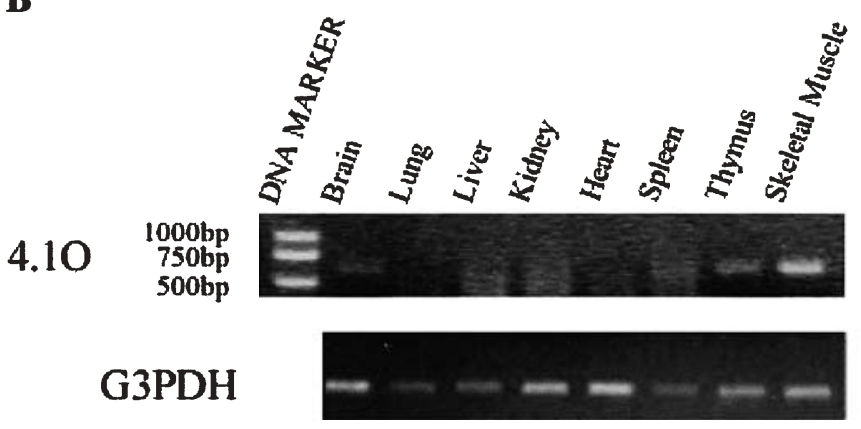

skeletal muscle, with lower levels in thymus and brain. Northern blot analysis showed that 4.1B was expressed in brain, placenta, kidney, heart, lung, pancreas, and skeletal muscle (Parra et al. 2000). Interestingly, the expression pattern of the human 4.10 gene in 16 tissues reveals a transcript only in ovary, which is different from that of 4.1B. Because 4.1B was considered a protein 4.1 tumor suppressor, we also checked $4.1 \mathrm{O}$ in a human tumor panel. Interestingly, no specific band of the transcript could be detected, particularly in ovarian carcinoma GI-102. Our data reveal that there is a transcript in normal ovary but not in ovarian carcinoma GI-102. This result indicates that $4.1 O$ may be associated with ovary tumor. Future studies will focus on the expression and function of the $4.1 \mathrm{O}$ protein, and the role of human 4.10 .

Acknowledgments This research was funded by a grant from the Natural Science Foundation of China (30170345).

\section{References}

Chishti AH, Kim AC, Marfatia SM, Lutchman M, Hanspal M, Jindal H, Liu SC, Low PS, Rouleau GA, Mohandas N, Chasis JA, Conboy JG, Gascard P, Takakuwa Y, Huang SC, Benz EJ Jr, Bretscher A, Fehon RG, Gusella JF, Ramesh V, Solomon F, Marchesi VT, Tsukita S, Tsukita S, Arpin M, Louvard D, Tonks NK, Anderson JM, Fanning AS, Bryant PJ, Woods DF, Hoover KB (1998) The FERM domain: a unique module involved in the linkage of cytoplasmic proteins to the membrane. Trends Biochem Sci 23:281-282
Gutmann DH, Donahoe J, Perry A, Lemke N, Gorse K, Kittiniyom K, Rempel SA, Gutierrez JA, Newsham IF (2000) Loss of DAL-1, a protein 4.1-related tumor suppressor, is an important early event in the pathogenesis of meningiomas. Hum Mol Genet 9:1495-1500

Gutmann DH, Hirbe AC, Huang ZY, Haipek CA (2001) The protein 4.1 tumor suppressor, DAL-1, impairs cell motility, but regulates proliferation in a cell-type-specific fashion. Neurobiol Dis 8:266278

Lombardo CR, Willardson BM, Low PS (1992) Localization of the protein 4.1-binding site on the cytoplasmic domain of erythrocyte membrane band 3. J Biol Chem 267:9540-9546

Marfatia SM, Lue RA, Branton D, Chishti AH (1995) Identification of the protein 4.1 binding interface on glycophorin $\mathrm{C}$ and p55, a homologue of the Drosophila discs-large tumor suppressor protein. J Biol Chem 270:715-719

Mattagajasingh SN, Huang SC, Hartenstein JS, Snyder M, Marchesi VT, Benz EJ (1999) A nonerythroid isoform of protein 4.1R interacts with the nuclear mitotic apparatus (NuMA) protein. J Cell Biol 145:29-43

Nunomura W, Takakuwa Y, Tokimitsu R, Krauss SW, Kawashima M, Mohandas N (1997) Regulation of CD44-protein 4.1 interaction by $\mathrm{Ca}^{2+}$ and calmodulin. J Biol Chem 272:30322-30328

Parra M, Gascard P, Walensky LD, Gimm JA, Blackshaw S, Chan N, Takakuwa Y, Berger T, Lee G, Chasis JA, Snyder SH, Mohandas N, Conboy JG (2000) Molecular and functional characterization of protein $4.1 \mathrm{~B}$, a novel member of the protein 4.1 family with high level, focal expression in brain. J Biol Chem 275:3247-3255

Pasternack GR, Anderson RA, Leto TL, Marchesi VT (1985) Interactions between protein 4.1 and band 3 . An alternative binding site for an element of the membrane skeleton. J Biol Chem 260:3676-3683

Schischmanoff PO, Winardi R, Discher DE, Parra M, Bicknese SE, Witkowska HE, Conboy JG, Mohandas N (1995) Defining of the minimal domain of protein 4.1 involved in spectrin-actin binding. $\mathrm{J}$ Biol Chem 270:21243-21250

Takakuwa Y (2000) Protein 4.1, a multifunctional protein of the erythrocyte membrane skeleton: structure and functions in erythrocytes and nonerythroid cells. Int J Hematol 72:298-309 
Tanaka T, Kadowaki K, Lazarides E, Sobue K (1991) Ca2(+)-dependent regulation of the spectrin/actin interaction by calmodulin and protein 4.1. J Biol Chem 266:1134-1140

Tran YK, Bogler O, Gorse KM, Wieland I, Green MR, Newsham IF (1999) A novel member of the NF2/ERM/4.1 superfamily with growth suppressing properties in lung cancer. Cancer Res 59:35-43

Walensky LD, Gascard P, Fields ME, Blackshaw S, Conboy JG, Mohandas N, Snyder SH (1998) The 13-kD FK506 binding protein,
FKBP13, interacts with a novel homologue of the erythrocyte membrane cytoskeletal protein 4.1. J Cell Biol 141:143-153

Ward RE IV, Lamb RS, Fehon RG (1998) A conserved functional domain of Drosophila coracle is required for localization at the septate junction and has membrane-organizing activity. J Cell Biol 140:1463-1473 